\title{
Physical Fitness Test (PFT) in Police and Military in Brazil: A Systematic Review
}

Bráulio Nascimento Lima, ${ }^{1,2}{ }^{\circledR}$ Renato Silveira de Assis Junior, ${ }^{1}$ Klebson da Silva Almeida, $^{3}{ }^{\circledR}$ Leandro Borelli de Camargo, ${ }^{1 \oplus}$ Ricardo Pablo Passos, ${ }^{1 \oplus}$ Carlos Henrique Prevital Fileni, ${ }^{\circledR}$ Divaldo Martins de Souza, ${ }^{4}{ }^{\oplus}$ Guanis de Barros Vilela Junior ${ }^{\circledR}$

Universidade Metodista de Piracicaba (UNIMEP), Piracicaba, SP - Brazil

Anhanguera Educacional Ltda, ${ }^{2}$ Valinhos, SP-Brazil

Universidade da Amazônia (UNAMA), ${ }^{3}$ Belém, PA - Brazil

Universidade do Estado do Pará (UEPA), ${ }^{4}$ Belém, PA - Brazil

\section{Abstract}

Background: Physical Fitness Tests (PFTs) are part of military routines and are usually administered to applicants for the Brazilian corps member, including the civil police.

Objective: To identify in the literature, scientific articles aimed at assessing physical fitness of police and military personnel in Brazil, using PFTs.

Methods: This was a systematic review, using the PRISMA systematization, using the following search keywords "police", "military", "physical fitness test" and " PFT", in English and Portuguese. The databases used were ScienceDirect, PubMed, BVS (Lilacs) and Scielo. Only original works performed with police and military personnel in Brazil were selected, through the application of inclusion and exclusion criteria.

Results: After the screening process, 11 articles were selected from a total of 1,487.

Conclusions: The data collected from the selected articles suggest that older age is related to a decrease in physical fitness, and better performance in the tests is related to a lower risk of comorbidities. Although high-intensity training improves physical fitness and anthropometric data, it is associated with injury rates; physically active lifestyle is associated with better flexibility.

Keywords: Police; Military Personnel; Exercise Test; Brazil.

\section{Introduction}

The Armed Forces are in charge of guaranteeing of the Brazil State, and their performance is based on the existence of the state, enforcing constitutional norms and principles throughout the territory. ${ }^{1}$ The military police act in direct contact with the civilian population and work to protect their lives and freedom based on their rights and duties. ${ }^{2}$ The civil police act in the judicial police branch of the criminal justice system. ${ }^{3}$

The police and military work require a wide range of physical abilities, and basic physical fitness must be displayed by all staff members. ${ }^{4,5}$ In this context, the assessment of physical abilities, by means of Physical Fitness Tests (PFTs), is routinely performed among the military personnel, and is also part of the tests for entry into the corps including the civil police. ${ }^{6,7}$

However, although PFT may be present in military routines and is usually administered to eligible applicants, periodic follow-up examinations are not common. In this sense, studies aimed at clarifying the purposes and applicability of PFTs and contributing to develop standardized protocols seem necessary .

The main objective of this study was to identify in the literature, scientific articles published from inception until May 17, 2020, related to physical fitness tests applied 
among the police and military personnel in Brazil. The secondary objective was to present the main results and conclusions obtained from the selected articles and discuss the purposes of the PFTs. This article sought to answer the following guiding questions: 1) What are the most commonly used tests? 2) What did the authors conclude from the results? 3) When available, how were anthropometric parameters assessed, and how did they affect the results?

\section{Methods}

This study was approved by PROSPERO (identification code CRD42020186880). First, a search was conducted in the ScienceDirect, PubMed, BVL (Lilacs) and Scielo databases to identify articles on the topic. The first phase of the search conducted on May 17, 2020, and considered all articles published up to that date. The keywords, in Portuguese and in English, used for the search, are listed in Table 1.

The following resources were used in the databases: "Research Articles" in ScienceDirect; "Clinical Trial" and "Randomized Controlled Trial" in PubMed; "Aptidão física", "Militares" and "Polícia" in BVS (Lilacs); "Health Sciences" and "Biological Sciences" in Scielo.

Data of articles retrieved from the search were exported to the EndNote ${ }^{\circledR}$ program. The systematic review was made using the PRISMA flow diagram. ${ }^{8}$ In the screening stages, the inclusion and exclusion criteria described in Table 2 were used. The first screening was made based on titles and summary/abstract of the exported citations. The remaining articles were downloaded and included in the EndNote ${ }^{\circledR}$ program for the second screening, based on full reading of the articles.

After the screening phases, a total of seven parameters were extracted from the selected articles - author, year of publication, sample characteristics, methods adopted, tests used, results obtained and main conclusions.

\section{Results}

The processes of data acquisition and sorting are shown in a flowchart in Figure 1. The search for articles in the Portuguese language yielded fewer articles than the search for articles in the English. General results of the search in each database are presented in Figure 1.

Table 1 - Search terms and databases used in review

Keywords by database

ScienceDirect; PubMed; Scielo; BVS (Lilacs)

((police) or (military)) and (fitness test) and not (review)

Scielo; BVS (Lilacs)

((polícia) or (militar)) and ((teste de aptidão física) or (taf)) and not (revisão)

Source: Author.

Table 2 - Inclusion and exclusion criteria for study selection

\begin{tabular}{lc}
\hline Inclusion criteria & Exclusion criteria \\
\hline - The study sample was composed of police and/or military personnel in Brazil & $\bullet$ Animal experiments \\
\hline - Studies involving physical fitness tests. & $\begin{array}{c}\bullet \text { Studies where physical fitness tests were used to assess } \\
\text { patients with diseases or pathological conditions }\end{array}$ \\
\hline$\bullet$ Original, complete articles published in scientific journals. & $\begin{array}{c}\text { Studies evaluating the performance of police or military } \\
\text { personnel in specific sports or physical exercises }\end{array}$ \\
\hline - Only studies with active police and/or military personnel. & $\bullet$ Interventions on nutritional supplementation \\
\hline Source: Author: & $\bullet$ Review articles, guidelines, and positioning articles \\
\hline
\end{tabular}




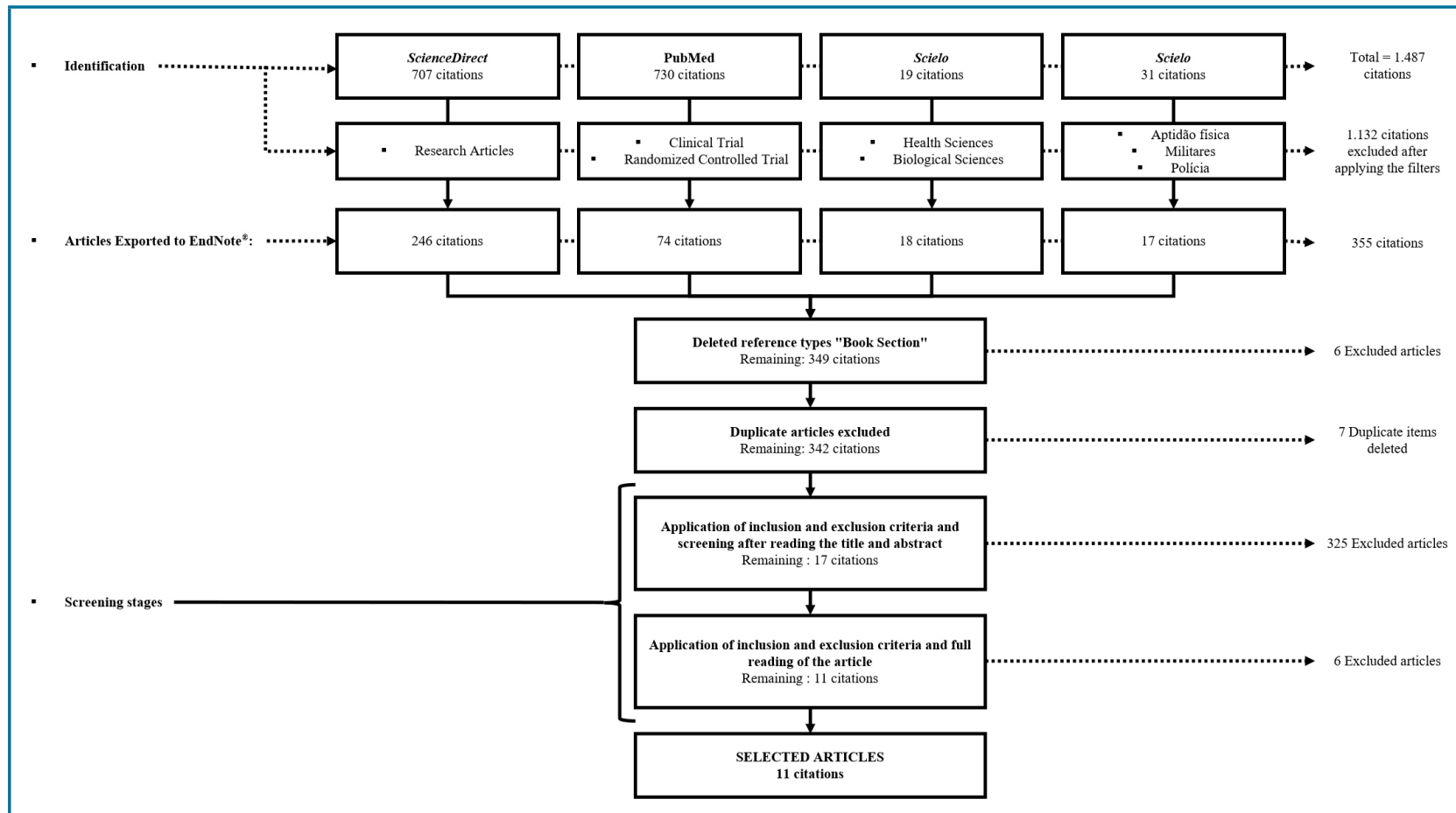

Figure 1 - PRISMA flow chart of screening and selection process

After exporting the data, six citations, specified as "Book Selection", were excluded. Eleven articles were selected and included in this study; the oldest article published in 2006 and the most recent published in 2020. Table 3 summarizes methodological characteristics, results and main conclusions of each article.

The most reported tests were one-minute sit-ups $(1 \mathrm{MA})^{9-13,15,16,19}$ and 12-minute run/walk, both in eight articles (72.7\%); ;,12,14-19 followed by push-ups in five articles (45.5\%); $i^{10,11,12,15,19}$ pull-ups in four articles (36.4\%); ; ${ }^{912,13,18}$ Flexitest (FT) in two articles (18.18\%); ; 11,19 and running tests $(3,200 \mathrm{~m}, 1,600 \mathrm{~m}$, or $50 \mathrm{~m}), 13,17,9$ treadmill stress test (TST), ${ }^{11}$ shuttle run $(\mathrm{SR})^{10}$ test, the Wells bench $(\mathrm{WB})^{10}$ test, and 100-meter swimming test $(100 \mathrm{mST})^{13}$ in one article each $(12.5 \%)$.

As for the experimental design, five $(45.5 \%)^{11,12,15,18,19}$ articles with descriptive statistics were identified, four $(36.4 \%)^{12-14,16}$ registry data evaluation, two $(18.2 \%)^{10,13}$ made comparisons between groups, one $(9.1 \%)^{17}$ comparison between tests and one $(9.1 \%)^{9}$ comparisons between conditions before and after intervention, and one articles used more than one of methods. ${ }^{9}$

Nine articles used anthropometric evaluation nine involving measurement of body mass index (BMI) $(81.8 \%)^{9-11,13,14,16-19}$, four $\% \mathrm{BF}(36.6 \%)^{10,11,16,18}$, three waist circumference (WC) $(27.3 \%)^{10,11,14}$ and one waisthipratio $(9,1 \%)^{11}$. One article reported hemodynamic data on systolic blood pressure (SBP) and diastolic blood pressure (DBP) $(9.1 \%)^{11}$; and one evaluated perception of effort $(9.1 \%)^{17}$, and one article $(9.1 \%)^{9}$ evaluated injuries during the intervention.

Among the selected articles, in five the deleterious effects of aging sensitive to the performance of the TAF were reported. . $^{10,12,13,15,19}$

\section{Discussion}

The present study presented studies involving PFTs applied to police and military personnel in Brazil, with no comparisons with data from other countries.

We did not find any article with civilian police officers, possibly because PFTs are not part of the routine of these policemen during their career.

Anthropometric and hemodynamic assessments are performed during the health examination, separate from the PFT. However, anthropometric, and hemodynamic measures may change after completion of the PFT. .20, 21

To answer the guiding questions of this study, the selected articles will be discussed starting from the PFTs, followed by a kinesiological analysis, and presentation of the main conclusions drawn from the data collected. 


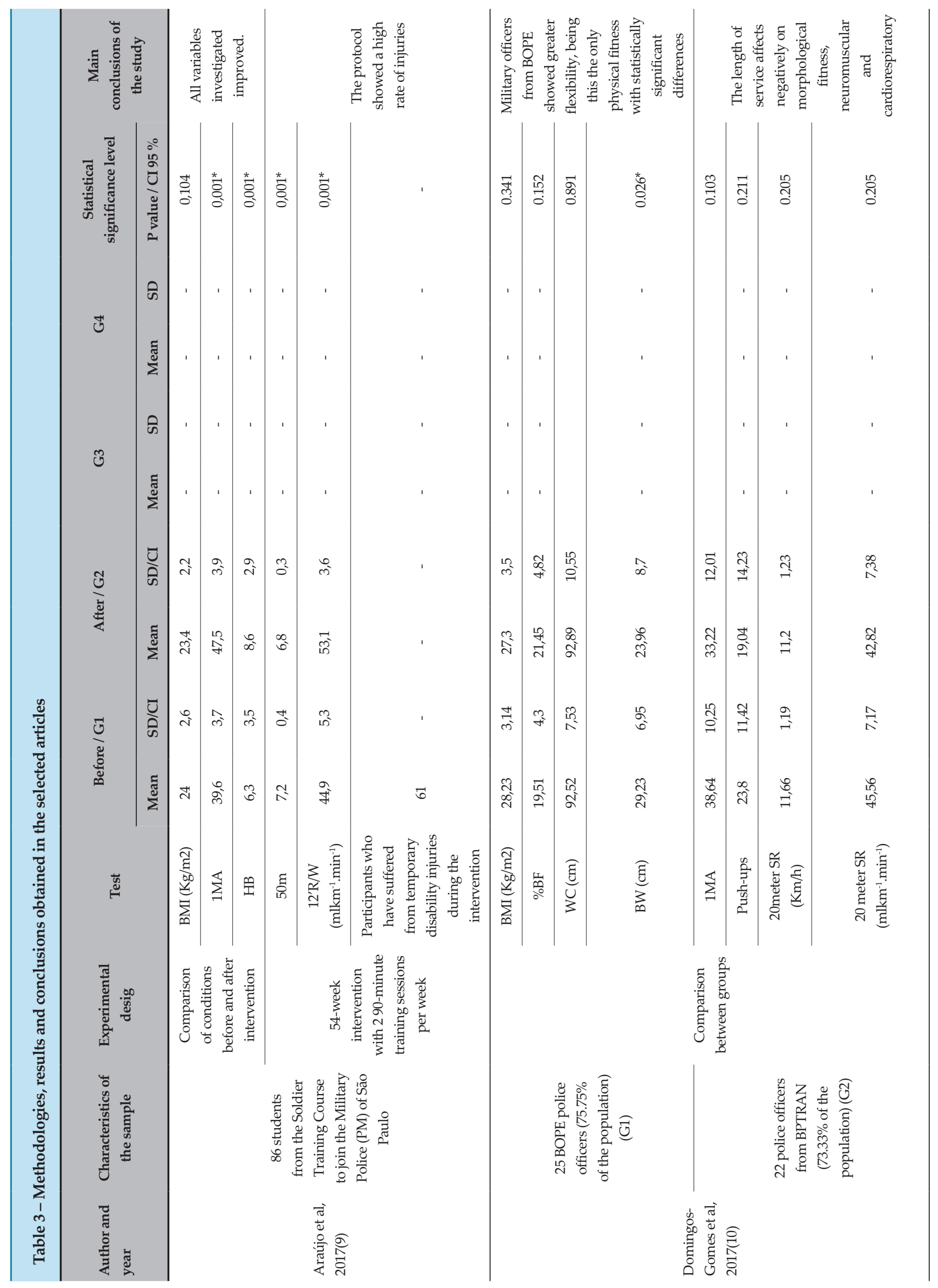




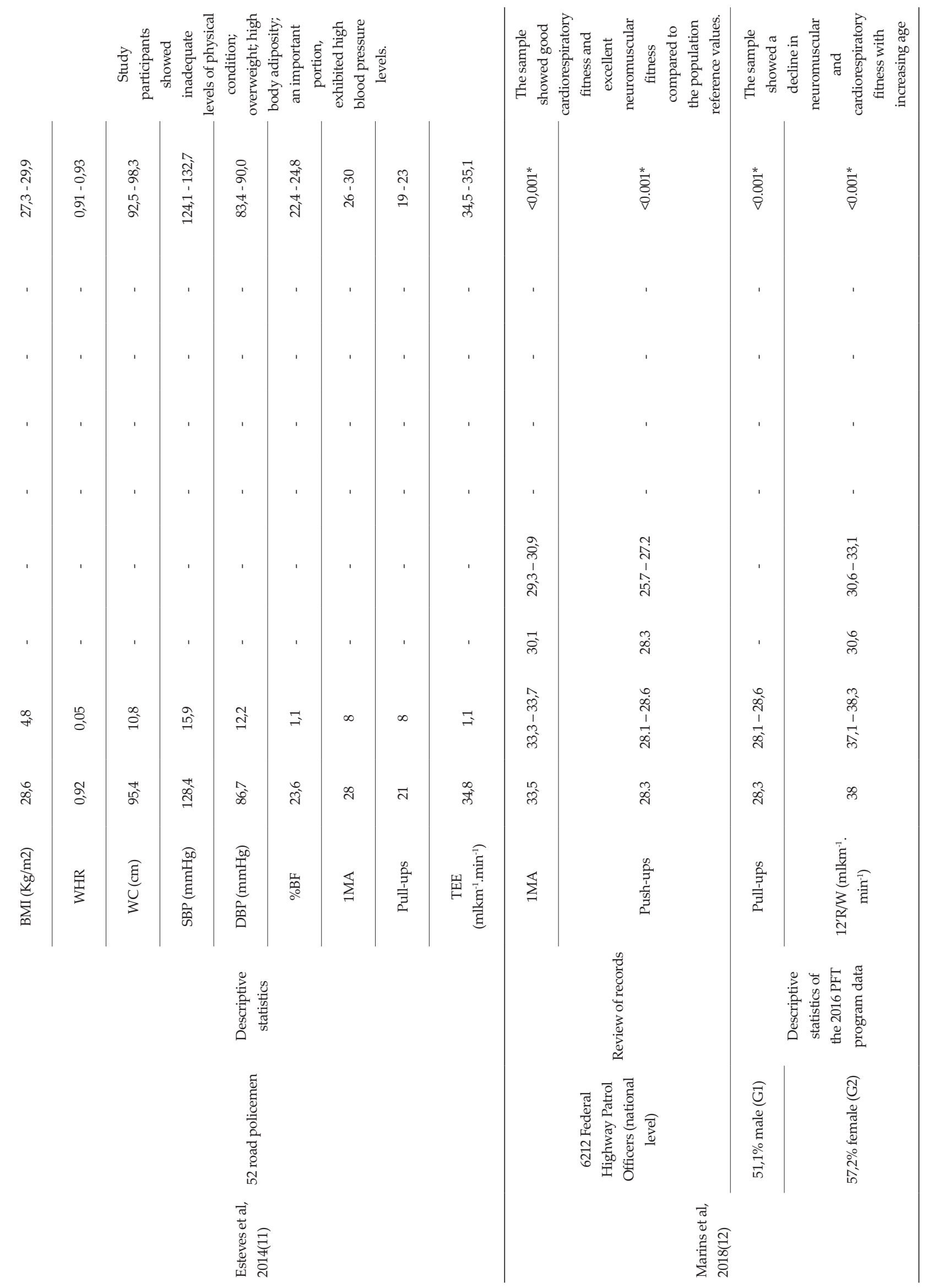




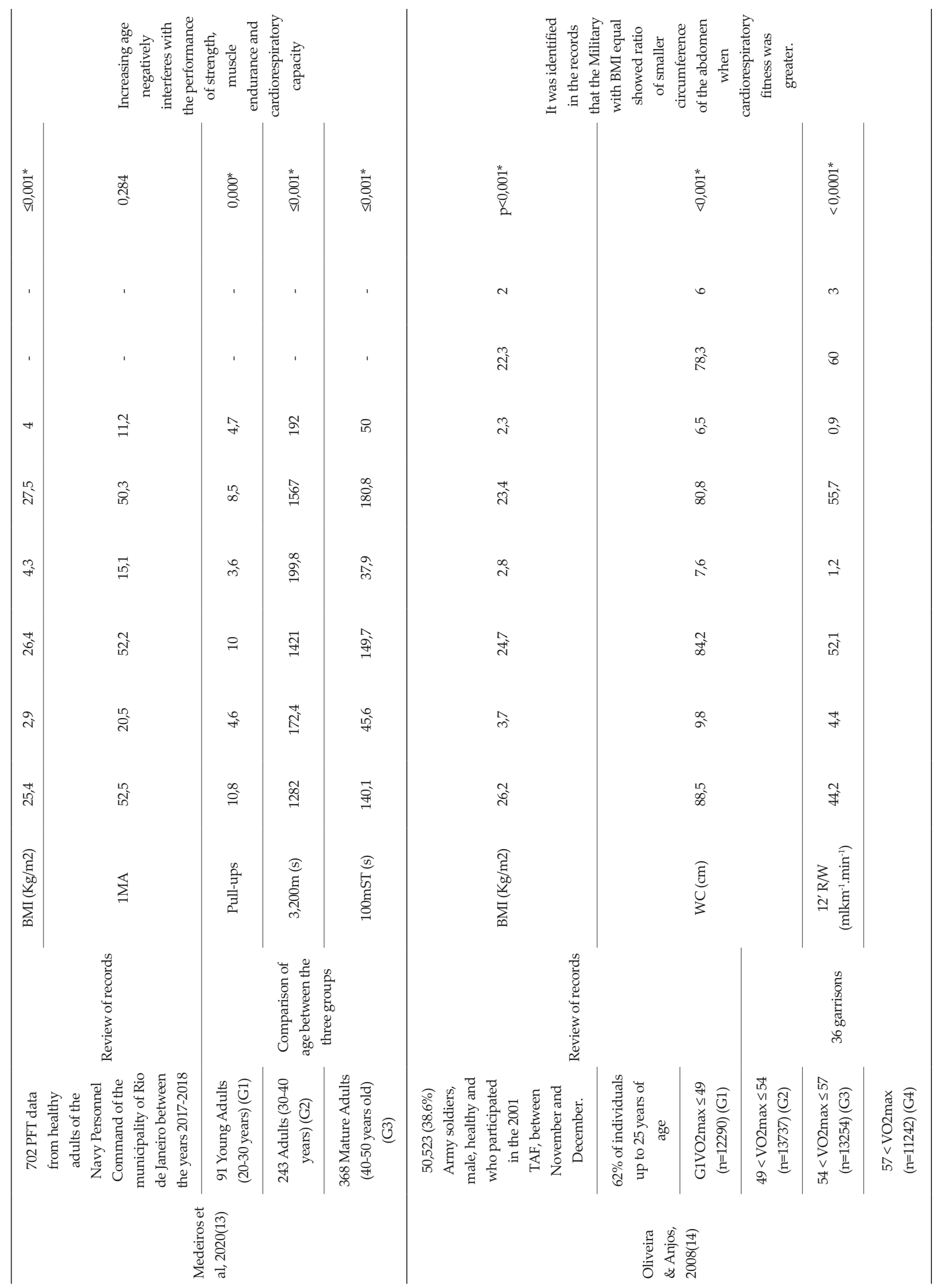




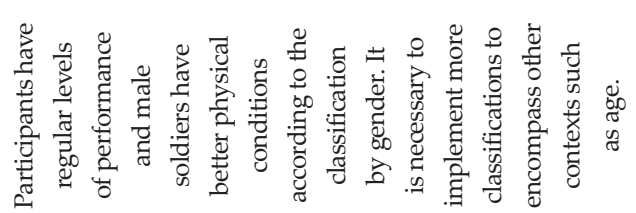

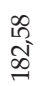

$\infty$
$\infty$
$\stackrel{0}{0}$
$\stackrel{0}{0}$

สี่

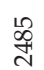

్ㅗㅇ

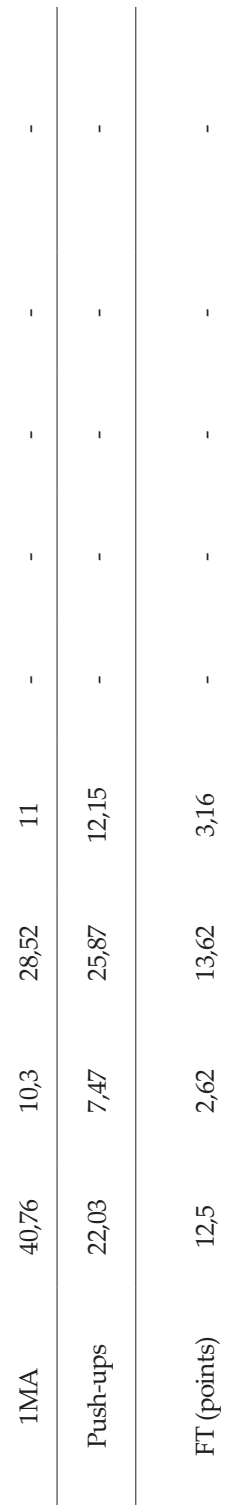

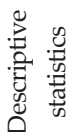

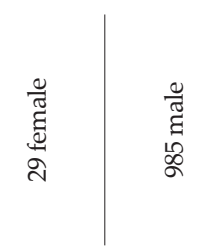

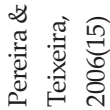

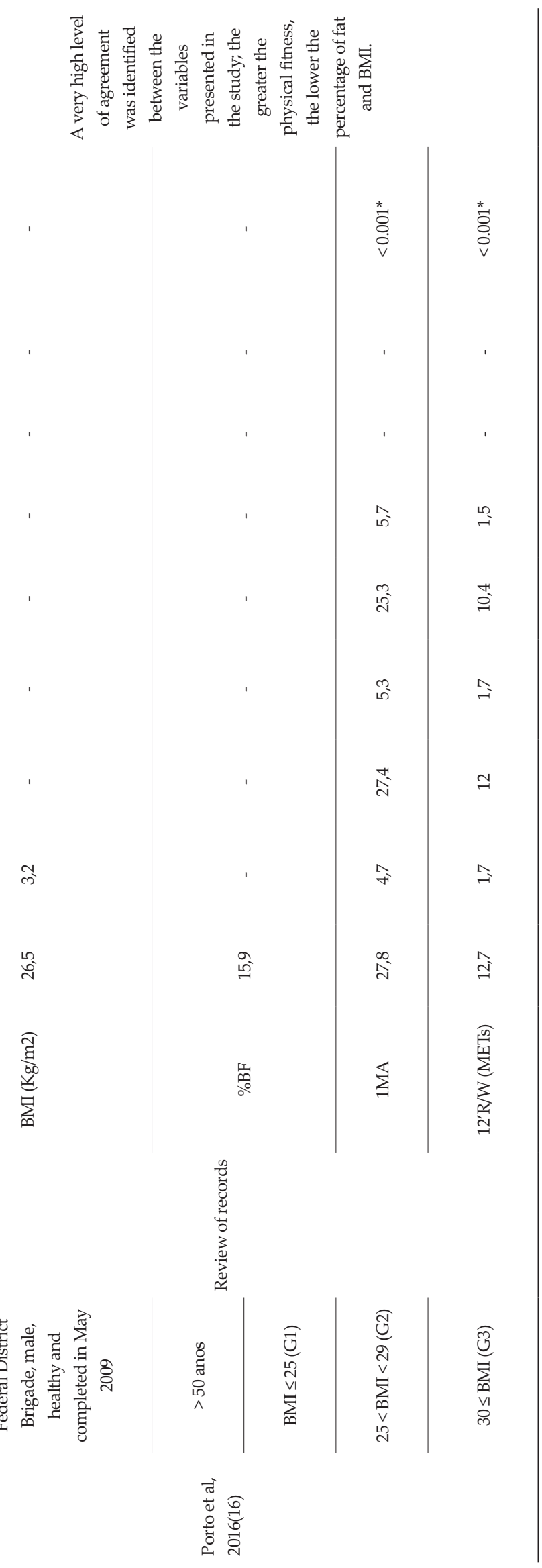




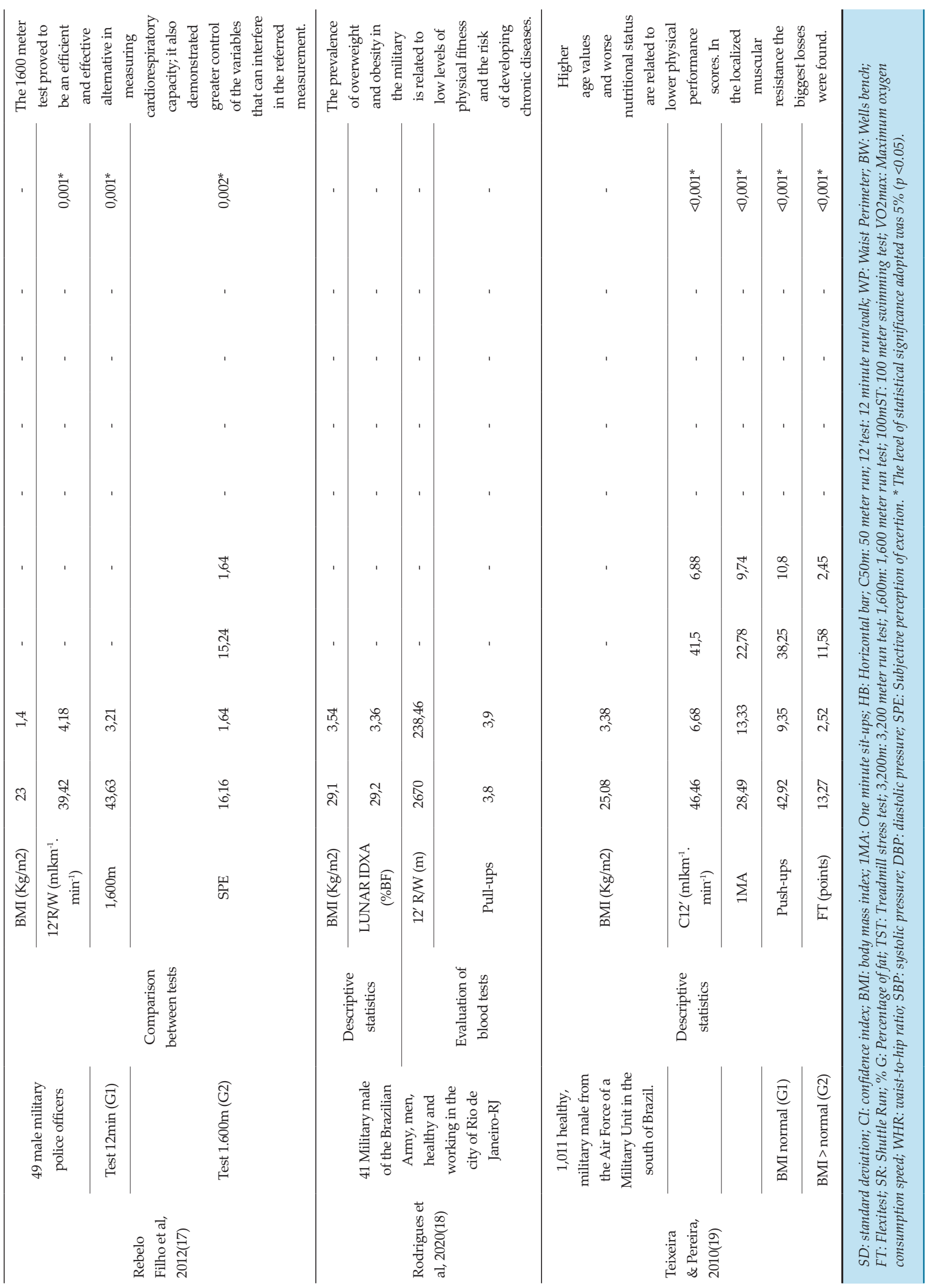


The most reported tests in the selected articles were $1 \mathrm{MA}$ and 12 -minute walk/run $(72.73 \%)$. In the 1MA test, the subject lies down on the back, with the knees bent, the soles of the feet resting on the ground, and arms crossed over the chest. Participant's feet are firmly held down by another person. In the up position, the subject should touch elbows to knee and then return down until their shoulder blades contact the floor. The participant performs as many correct sit ups as possible in 60 seconds. ${ }^{9-13,15,16,19}$ In the article by Rodrigues et al. ${ }^{18}$ the numbers of sit ups were considered inadequate, which was related to high values of BMI. In the article by Esteves et al. ${ }^{11}$ conditioning was also considered inappropriate, however, BMI was classified as normal, and thus, the relationship between BMI and physical fitness was found. In the other articles, the values of the 1MA test were considered satisfactory. The data suggest that BMI may negatively influence the performance of the 1MA test, but it is not decisive.

In the 12-minute run/walk test, participant lines up behind the starting line. After a command, the watch is started, participants should walk or run, and the longest distance covered in 12 minutes is recorded. Then, estimated VO2 Max results are calculated by specific formulas. ${ }^{9} 12,14-19$ Results of the selected articles suggest that the increase in age, $\mathrm{BMI}$ and \% BF negatively affect the performance in the 12-minute walk/run test. ${ }^{12,16,18}$ Also, individuals with better performance had lower BMI and Waist Perimeter (WP). ${ }^{14}$

The $3,200 \mathrm{~m}, 1,600 \mathrm{~m}, 20 \mathrm{~m}$ ST and TST $(9,1 \%)$ were also used for cardiac evaluation. In the $50 \mathrm{~m}, 3,200 \mathrm{~m}$ and $1,600 \mathrm{~m}$ tests, the time required to cover the distances of $50 \mathrm{~m}, 3,200 \mathrm{~m}$ and $1,600 \mathrm{~m}$, respectively is recorded. ${ }^{9,13,17}$ The shuttle run test of running back and forth, repeatedly, a distance of 20 meters, controlled by a sound stimulus. ${ }^{10}$ TST was performed following a specific protocol, monitored by electrocardiography; the test was performed which made it possible to collect hemodynamic data. ${ }^{11}$ The VO2max calculations were based on doubly indirect assessments. Despite the methodological differences, these studies supported the statement that cardiorespiratory performance decreases with increasing age. ${ }^{10,12,13,15,19}$

Push-up test was the third most reported (45.5\%). Before beginning the push-up movement, participants assume the front-leaning rest position by placing the hands comfortably and feet together. The body should form a straight line from the shoulders to the ankles, with the elbows extended. Push-ups are begun by bending the elbows and lowering the entire body until the upper arms are at least parallel to the ground. Then participants return to the starting position by raising the body until the arms are fully extended. The movement is repeated continuously until failure. For women, the exercise may be adapted by performing the exercise with the knees on the floor (knee push-ups). 10-12,15,19 In the test, the number of correct repetitions is counted. The activity load is based on body mass, therefore, the anthropometric characteristics interfere with the test performance. A In that test the number of repetitions is counted to compose the test score and higher values represent the performance. As the activity load is based on body mass, anthropometric characteristics influence the test performance. This is corroborated by the study by Esteves et al., ${ }^{11}$ who reported inadequate levels of physical condition in highway police officers. In addition, other studies reinforced the negative effect of age on the performance in push-up tests. ${ }^{10,12,15,19}$ According to Pereira \& Teixeira, ${ }^{15}$ there should be an age categorization when applying the test and evaluating performance.

In the pull-up test $(36.4 \%)$, the participant stands below a pull-up bar and, with elbows fully extended, place their hands in pronation in the bar. Then, participant bends the elbows and raises the upper body up toward the bar until the chin is over the bar. The movement is repeated until failure or until completing 60 seconds. An alternative or adapted version consists of maintaining the elbows at $90^{\circ}$ in isometry; higher repetition values represent higher scores or better performance. ${ }^{9,12,13,18}$ This test aims to assess muscle strength or endurance depending on the level of training and body mass. ${ }^{22,23}$

The $100 \mathrm{mST}(9.1 \%)$ consists of performing a free swimming test in a 50 meter-pool. Participants start by jumping from a platform, touch the opposite end and swim back to the staring edge. Shorter times indicate better performance. ${ }^{13}$ Medeiros et al. ${ }^{13}$ also reported a decrease in the performance in the $100 \mathrm{mST}$ with increasing age.

Two articles used flexibility tests, the WB test and the FT $(9.09 \%)$. In the BW test, also known as the sit and reach test, participants sit on the floor with the legs stretched out together, and knees extended. With the hands superimposed and palms facing downwards, participants reach forward along the measuring line as far as possible, performing hip 
and trunk flexion. The participant has three attempts to reaches the maximum distance; greater distances correspond to better performance. ${ }^{10}$ The FT is a test that qualitatively evaluates joint amplitudes in five movements - extension with adduction of the shoulder, horizontal adduction of the shoulder, flexion of the trunk, flexion of the hip and the abduction of the hip. The movements are rated from 0 to 4 and provide a global score called Flexindex. According to DomingosGomes et al., ${ }^{10}$ flexibility can be influenced by lifestyle, and sedentarism is associated with less flexibility. Although older age can contribute to lower flexibility, it does not appear to be as determinant as in other physical capacities. Higher BMI values are related to lower mobility. ${ }^{15,19}$

Araújo et al., ${ }^{9}$ used a 54-week intervention protocol, including 90 minutes of aerobic, recreational and sports activities, twice a week and during. Results of PFTs and anthropometric assessment showed improvements after the intervention protocol. In that article, a high rate of injuries was also observed during the intervention protocol, which was related to high training intensity.

BMI was the most common anthropometric parameter measured in the studies selected, assessed in nine of the 11 studies included. ${ }^{9-11,13,14,16-19} \mathrm{BMI}$ is suitable for assessing the nutritional status of populations, and widely applied in samples with certain homogeneity. ${ }^{24}$

The $\% \mathrm{G}$ can present personalized data of the subjects evaluated. This parameter was assessed in three of the 11 articles included, in 52, 50 and 41 participants. This relatively small number of participants made the individual evaluation viable. ${ }^{10,11,18}$

Subjective perception of exertion (SPE), also known as the Borg Scale, is not a PFTs, but rather a scale-based instrument used to measure an individual's effort and exertion during physical work. The instrument was used in one article only. ${ }^{17}$

Measures involving WC, WHR, SBP and DBP were used to assess the risk of comorbidities. ${ }^{10,11,14}$ Esteves et al. ${ }^{11}$ identified, in a sample of highway police officers, low performance in PFTs and worrying data regarding these measurements. Results of the selected articles suggest that better results in PFTs are related to better values of WC, WHR, SBP and DBP, i.e., lower risk of comorbidities.

It is important to note that this review study had some limitations in its construction, such as the scarcity of articles on the developed theme, as well as the great heterogeneity regarding the protocols applied in the PFTs of the selected studies. Thus, it is evident that there is no standard protocol to be followed in PFT applied to military personnel in Brazil.

\section{Conclusion}

The present study brought to light studies involving PFTs in police and military personnel in Brazil. The most used tests were 1MA, the 12-minute run walk test, push-ups, pull-ups, the FT, running tests $(3,200 \mathrm{~m}, 1,600 \mathrm{~m}$, and $50 \mathrm{~m})$, TST, SR test, WB test, and $100 \mathrm{mST}$. The tests aimed at assessing cardiorespiratory fitness, strength, muscular endurance, flexibility, running speed and swimming speed. No articles with civil police officers were found, but only with military police officers. Age and length of service were related to decreased physical fitness, whereas better performance in PFTs were related to decreased risk of comorbidities. Training protocols involving high intensity may be related to significant improvements in PFTs and anthropometric data, however, they can generate high injury rates. More physically active lifestyle can be related to greater flexibility. Further studies involving PFTs with military personnel should be carried out, especially clinical trials, to determine which tests are the most suitable to assess and measure the various physical capacities involved in military service, and allow the development of a single, standardized PFT protocol to assess this population in the various military forces in Brazil.

\section{Author contributions}

Conception and design of the research: Lima BN, Assis Junior RS, Vilela Junior GB. Acquisition of data: Lima BN, Assis Junior RS, Vilela Junior GB. Analysis and interpretation of the data: Lima BN, Assis Junior RS, Almeida KS, Camargo LB, Passos RP, Fileni CHP, Souza DM, Vilela Junior GB. Statistical analysis: Lima BN, Vilela Junior GB. Writing of the manuscript: Lima $\mathrm{BN}$. Critical revision of the manuscript for intellectual content: Lima BN, Assis Junior RS, Almeida KS, Camargo LB, Passos RP, Fileni CHP, Souza DM, Vilela Junior GB. Screening of the data: Lima BN, Assis Junior RS, Almeida KS, Camargo LB, Passos RP, Fileni CHP, Souza DM, Vilela Junior GB. 


\section{Potential Conflict of Interest}

No potential conflict of interest relevant to this article was reported.

\section{Sources of Funding}

There were no external funding sources for this study.

\section{References}

1. Campos JGS. A Decretação das Operações de Garantia da Lei e da Ordem na Defesa do Estado Pelas Forças Armadas. Rev Ambient: Gest e Desenvolv. 2019;12(1):64-70. doi: 10.24979/195.

2. Cruz DS, Lara LD. A Importância da Qualidade no Atendimento Prestado Pela Polícia Militar: O que Dizem as Pessoas Atendidas Pelo $10^{\circ}$ Batalhão da Polícia Militar do Município de Luziânia-GO. Rev. bras. segur. pública. 2018;11(1)114-24. doi: 10.29377/rebesp.v11i1.

3. Greco R. Atividade Policial: Aspectos Penais, Processuais Penais, Administrativos e Constitucionais. 10th ed. Niterói: Impetus; 2020.

4. Shakibaee A, Rahimi M, Bazgir B, Asgari AR. A Review on Physical Fitness Studies in Military Forces. EBNESINA. 2015;16(4):64-79.

5. Herrador-Colmenero M, Fernández-Vicente G, Ruíz JR. Assessment of Physical Fitness in Military and Security Forces: A Systematic Review. Eur. J. Hum. Mov. 2014(32):3-28.

6. Lentz L, Randall JR, Guptill CA, Gross DP, Senthilselvan A, Voaklander D. The Association Between Fitness Test Scores and Musculoskeletal Injury in Police Officers. Int J Environ Res Public Health. 2019;16(23):4667. doi: 10.3390/ijerph16234667.

7. Wilson JN, Markey CN, Markey PM. Fitness correlates of Obligatory Versus Health Motives for Exercise: An Examination of Men in the Military. Psychol Sport Exerc. 2012;13(4):371-7. doi: 10.1016/j. psychsport.2012.01.002

8. Liberati A, Altman DG, Tetzlaff J, Mulrow C, Gøtzsche PC, Ioannidis JP, et al. The PRISMA Statement for Reporting Systematic Reviews and Meta-Analyses of Studies That Evaluate Health Care Interventions: Explanation and Elaboration. PLoS Med. 2009;6(7):e1000100. doi: 10.1371/ journal.pmed.1000100.

9. Araújo LGM, Sanches M, Turi BC, Monteiro HL. Aptidão Física e Lesões: 54 Semanas de Treinamento Físico com Policiais Militares. Rev Bras Med Esporte. 2017;23(2):98-102. doi: 10.1590/1517-869220172302158877.

10. Domingos-Gomes JR, Oliota-Ribeiro LS, Silva JS, Melo AC, Albuquerque Neto SL, Cirilo-Sousa MS, et al. Comparison of Health-Related Physical Fitness and its Association with the Length of Service Between Special Operations and Traffic Military Police Officers. J Phys Educ. 2017;27(e2743)1-12. doi: 10.4025/jphyseduc.v27i1.2743.11. Esteves JVDC, Andrade ML, Gealh L, Andreato LV, Moraes SMF. Caracterização da Condição Física e Fatores de risco cardiovascular de Policiais Militares Rodoviários. Rev Andal Med Deporte. 2014;7(2):66-71. doi: 10.1016/ S1888-7546(14)70064-4

12. Marins EF, Ferreira RW, Vecchio FBD. Cardiorespiratory and Neuromuscular Fitness of Federal Highway Police Officers. Rev Bras Med Esporte. 2018;24(6):426-31. doi: 10.1590/1517-869220182406185222.

\section{Study Association}

This study is not associated with any thesis or dissertation work.

\section{Ethics approval and consent to participate}

This article does not contain any studies with human participants or animals performed by any of the authors.

13. Medeiros FJ, Lourenço JVD, Aedo-Muñoz E, Perez DIV, Santos MAF Brito CJ, et al. Physical Fitness Test Performance Probability with Increasing Age: Suggestions for Practical Applications in Military Physical Training. Rev bras cineantropom desempenho hum. 2020;22(e71733):1-10. doi: 10.1590/1980-0037.2020v22e71733.

14. Oliveira EAM, Anjos LA. Medidas Antropométricas Segundo Aptidão Cardiorrespiratória em Militares da Ativa, Brasil [Anthropometry and Cardiorespiratory Fitness of Military Men in Active Duty, Brazil]. Rev Saude Publica. 2008;42(2):217-23. doi: 10.1590/s003489102008000200005.

15. Pereira ÉF, Teixeira CS. Proposta de Valores Normativos para Avaliação da Aptidão Física em Militares da Aeronáutica. Rev bras educ fís esp. 2006;20(4):249-56. doi: 10.1590/S1807-55092006000400003.

16. Porto LGG, Nogueira RM, Nogueira EC, Molina GE, Farioli A, Junqueira LF Jr, et al. Agreement Between BMI and Body Fat Obesity Definitions in a Physically Active Population. Arch Endocrinol Metab. 2016;60(6):51525. doi: 10.1590/2359-3997000000220.

17. Rebelo Filho G, Prada JA, Silva GCB, Gayoso Neto JCA, Santos FN, Feitosa RA, et al. Avaliação da Capacidade Cardiorrespiratória (VO2MÁX) em Policiais Militares, com Testes Indiretos. Rev bras ciênc mov. 2012;20(1):5-13. doi: 10.18511/rbcm.v20i1.3019.

18. Rodrigues LC, Fortes MSR, Lippert MAM, Rosa SED, Fernandes Filho J. Visceral Fat, Physical Fitness and Biochemical Markers of Brazilian Military Personnel. Rev Bras Med Esporte. 2020;26(1):21-4. doi: $10.1590 / 1517-869220202601187736$

19. Teixeira CS, Pereira EF. Aptidão física, idade e estado nutricional em Militares [Physical Fitness, Age and Nutritional Status of Military Personnel]. Arq Bras Cardiol. 2010;94(4):438-43. doi: 10.1590/s0066782x2010005000005.

20. Chaves LC, Posso MBS. Avaliação Física em Enfermagem. Barueri: Manole; 2012.

21. Heyward VH. Avaliação Física e Prescrição de Exercício: Técnicas Avançadas. 6th ed. Porto Alegre: Artmed; 2011.

22. Marinho BF, Marins JCB. Teste de força/resistência de Membros Superiores: Análise Metodológica e Dados Normativos. Fisioter. mov. 2012;25(1):219-30. doi: 10.1590/S0103-51502012000100021.

23. Lopes C, Marchetti P. Planejamento e Prescrição do Treinamento Personalizado do Iniciante ao Avançado. 2nd ed. Santa Barbara D'Oeste: Gráfica Mundo; 2018

24. Nuttall FQ. Body Mass Index: Obesity, BMI, and Health: A Critical Review. Nutr Today. 2015;50(3):117-28. doi: 10.1097/ NT.0000000000000092. 